\title{
Adaptations of Surgical Practice During the Covid-19 Pandemic: Report from a Pediatric Surgery Unit in Yaounde - Cameroon
}

\author{
Fossi Kamga Gacelle, Salihou Aminou Sadjo, Dikongue Caroline Eugenie, Tibizing Etoa Grace, Ishimwe \\ Umuhoza Noella Christine, Andze Ondobo Gervais, Mbouche Landry, Fru Angwafo III, and Faustin \\ Félicien Mouafo Tambo
}

Department of Surgery and Specialties, Yaoundé Gyneco-Obstetric and Pediatric Hospital, University of Yaoundé I, Cameroon

\begin{abstract}
The authors report on their experience of pediatric surgical practice in a COVID-19 epidemic situation in Yaoundé. They underline the specificities of the African setting, particularly in Cameroon, and outline the adaptations that are indispensable to curb the progression of the current pandemic in their practice environment. The proper use of available human resources, the temporary suspension of non-urgent outpatient visits, prioritization of emergency procedures exclusively and the promotion of day surgery as well as implementing a protein rich diet for all patients constituted the core of these adaptations.
\end{abstract}

\section{Keywords}

Adaptation, COVID-19, SARS-COV-2, Pediatric surgery, Yaoundé-Cameroon

\section{Introduction}

The COVID-19 pandemic has changed the organization of care around the world [1] and more specifically affected pediatric surgical practice. Africa in general, and Cameroon in particular, has not been exempted from the various measures taken here and there by governments to combat the transmission and limit the consequences of the SARS-COV-2 infection. In the pediatric surgery service of the Yaoundé Gynaeco-Obstetric and Paediatric Hospital (YGOPH) we have implemented a number of adaptations in our pediatric surgical practice. We wanted to report on this experience in the context of a low-income country.

\section{Observations}

- The SARS-COV-2 infection led to the creation in YGOPH, of a unit entirely dedicated to the management of COVID-19 patients. This resulted in the posting of some staff members in this unit, thereby reducing the health personnel in several units, notably the pediatric surgery unit which became deprived of 3 medical doctors and 4 nurses. Consequently, we had to readjust the calls duty roaster sso as to reduce the number of calls and favor home-based work with the principal objective of lengthening the personnel resting time and shortening the time spent in the hospital.

- The outpatient clinic was temporarily closed in our unit as a result of the COVID-19 pandemic and we gave priority only to urgent pediatric surgery consultations. In this emergency unit, social distancing measures, hand washing with water and soap, the use of hydro-alcoholic gels were systematic and only one parent or guardian was allowed to per child.

- In the operating room, we limited to 5 the number of personnel during surgeries including the anesthesia team, and we set up a unidirectional circuit to reduce contact between personnel. Only surgical emergencies were handled and due to our low hospital bed capacity ( 25 beds), day surgery was used whenever it was possible. Moreover,

*Corresponding author: Prof. Faustin Félicien Mouafo Tambo, Department of Pediatric Surgery and Specialties, Yaoundé Gyneco-Obstetric and Pediatric Hospital, University of Yaoundé I, Yaoundé 5790, Cameroon, Tel: +237-696098325

Received: May 13, 2020

Accepted: June 11, 2020

Published online: June 13, 2020

Citation: Gacelle FK, Sadjo SA, Eugenie DC, et al. (2020) Adaptations of Surgical Practice During the Covid-19 Pandemic: Report from a Pediatric Surgery Unit in Yaounde - Cameroon. Arch Pediatr Surg 4(1):64-65 
the classical approach was preferred over laparoscopy as pneumoperitoneum high-pressure trocar leaks enhance the risk of exposure to aerosol to operating theater staff.

- In the immediate post-operative period, an emphasis was laid on the improvement of the immune status of pediatric patients. A nutritional treatment including a protein rich diet and iron supplementation was systematic given the high frequency of protein energy malnutrition and iron deficiency anemia in our pediatric patients.

\section{Discussion}

The reduction of the time spent in the unit by our personnel was a means of protecting them from the SARS-CoV-2 infection considering that the hospital had become the place most likely to favor an encounter with a patient carrier of the coronavirus. This attitude led to the development of teleconsultation and an increase in the use of the mobile phones in our health care services.

The closing of outpatient consultations allowed the use of that space for the admission of suspected COVID-19 cases. In this space, ventilation and aeration were regular, the surfaces were systematically disinfected between 2 patients and the physician was equipped with a peculiar jumpsuit-type clothing to avoid any contact with the patient, his body fluids or the contaminated material.

Avoiding the use of the pediatric laparoscopy column during this period is backed by the findings of Tuech, et al. [1] that mentioned the risk of the presence of SARS-CoV- 2 in the pneumoperitoneum. Because of this, laparoscopy in the context of the COVID-19 pandemic constitutes a risk for operat- ing room staff and requires a good functioning of the aspiration system, the use as much as possible of balloon trocars to prevent leakages, not forgetting the smoke evacuators $[2,3]$.

Our special attitude regarding nutrition during the post-operative period has the assent of Liang $\mathrm{W}$, et al. in China [4]. The experience of our Chinese colleagues seems to show that patients with secondary immune depression are more likely to develop of a SARS-CoV-2 infection and to have an increased severity of the infection.

\section{Conclusion}

The implementation of these various adaptation measures in our unit could partly explain the encouraging results obtained so far in our setting in the fight against this pandemic.

\section{References}

1. Tuech JJ, Gangloff A, Di Fiore F, et al. (2020) Stratégie pour la pratique de la chirurgie digestive et oncologique en situation d'épidémie de COVID-19. Journal de Chirurgie Viscérale.

2. (2020) COVID-19: Considerations for optimum surgeon protection before, during and after operation. American College of Surgeons.

3. Min Huan Zheng, Luigi Boni, Abe Fingerhurt (2020) Minimally Invasive Surgery and the novel corona virus outbreak: Lessons learned in china and Italy. Annals of Surgery.

4. Liang W, Guan W, Chen R, et al. (2020) Cancer patients in SARSCoV-2 infection: A nation wide analysis in China. Lancet Oncol 21: 335-337.

DOI: $10.36959 / 472 / 356$ 